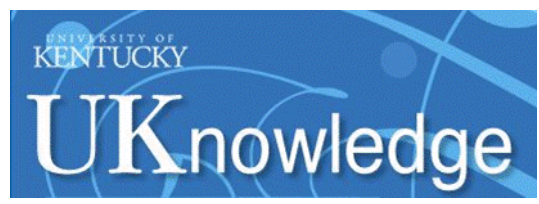

University of Kentucky

UKnowledge

$10-2019$

\title{
Military Coalitions and Crisis Duration
}

\author{
Daina Chiba \\ University of Essex, UK \\ Jesse C. Johnson \\ University of Kentucky, j.johnson@uky.edu
}

Follow this and additional works at: https://uknowledge.uky.edu/polsci_facpub

Part of the Political Science Commons

Right click to open a feedback form in a new tab to let us know how this document benefits you.

\section{Repository Citation}

Chiba, Daina and Johnson, Jesse C., "Military Coalitions and Crisis Duration" (2019). Political Science Faculty Publications. 6.

https://uknowledge.uky.edu/polsci_facpub/6

This Article is brought to you for free and open access by the Political Science at UKnowledge. It has been accepted for inclusion in Political Science Faculty Publications by an authorized administrator of UKnowledge. For more information, please contact UKnowledge@lsv.uky.edu. 


\section{Military Coalitions and Crisis Duration}

\section{Digital Object Identifier (DOI)}

https://doi.org/10.1086/704598

\section{Notes/Citation Information}

Published in The Journal of Politics, v. 81, no. 4.

(c) 2019 by the Southern Political Science Association. All rights reserved.

The copyright holder has granted the permission for posting the article here.

The corrigendum to this article is available at the end of the downloadable document. 


\title{
Military Coalitions and Crisis Duration
}

\author{
Daina Chiba, University of Essex \\ Jesse C. Johnson, University of Kentucky
}

Forming a military coalition during an international crisis can improve a state's chances of achieving its political goals. We argue that the involvement of a coalition, however, can have unintended adverse effects on crisis outcomes by complicating the bargaining process and extending the duration of crises. This argument suggests that crises involving coalitions should be significantly longer than crises without coalitions. However, other factors that affect crisis duration are also likely to influence coalition formation. Therefore, taking into account the endogeneity of the presence of a coalition is essential to testing our hypothesis. To deal with this inferential challenge, we develop a new statistical model that is an extension of instrumental variable estimation in survival analysis. Our analysis of 255 post-World War II interstate crises demonstrates that, even after accounting for the endogeneity of coalition formation, military coalitions tend to extend the duration of crises by approximately 284 days.

M ilitary coalitions are groups of states that collaborate during an international crisis to issue threats of collective military action. Acting through a military coalition rather than unilaterally can improve a state's chances of achieving its political goals. As a result, states involved in crises have incentives to form military coalitions. More than $20 \%$ of interstate crises from 1946 to 2001 involve a military coalition. ${ }^{1}$ The cost of forming a coalition is often understood as the compensation that must be provided to partners that may not have the same interests as the coalition builder (Wolford 2015). Thus, coalition builders face a trade-off between obtaining additional military power and making policy concessions to coalition partners.

We argue, however, that seeking the assistance of a coalition can come at an additional, potentially more deadly, cost. More specifically, coalitions can prolong international crises and increase the time participants spend bargaining under the threat of war. Our argument is based on the notion that the presence of a coalition can hinder the bargaining process that precedes any peaceful deal that is reached. A coalition adds the additional phase of bargaining between partners and complicates bargaining with the adversary.

Extending the duration of crises generates a variety of undesirable costs for the participants. The most obvious of these costs are those associated with being in a constant state of war preparedness. Crises often involve the mobilization of substantial amounts of troops and equipment, the procurement of armaments, regular surveillance of the opposition, and extensive war planning. In addition to these direct costs, there is a large body of evidence that suggests crises harm a participant's economy (e.g., Hoffmann and Neuenkirch 2017; Rigobon and Sack 2005; Zussman, Zussman, and Nielsen 2008). These direct and indirect costs continue to add up over the course of a crisis and come at the expense of other more productive ends, making prolonged crises exceptionally costly. Perhaps most concerning, however, is evidence that increased duration raises the chances of a crisis turning violent (DeRouen and Goldfinch 2005). This suggests that the involvement of a military coalition may not only raise the costs of the crisis for the participants but also put them at a greater risk for war.

Thus, estimating the effect of a military coalition on crisis duration is important to academics and policy makers alike. However, in estimating this relationship we face a significant inferential problem. Other factors that affect crisis duration are also likely to influence coalition formation. Disputants may prefer to form coalitions in crises that are particularly intractable. Thus, coalitions would tend to be present in crises that

Daina Chiba (dchiba@essex.ac.uk) is a senior lecturer in the department of government at University of Essex, Colchester, United Kingdom CO4 3SQ. Jesse C. Johnson (j.johnson@uky.edu) is an associate professor of political science at University of Kentucky, Lexington, KY 40506.

Data and supporting materials necessary to reproduce the numerical results in the article are available in the JOP Dataverse (https://dataverse.harvard.edu /dataverse/jop).

1. This figure is based on the data analyzed below.

The Journal of Politics, volume 81, number 4. Published online August 23, 2019. http://dx.doi.org/10.1086/704598

(C) 2019 by the Southern Political Science Association. All rights reserved. 0022-3816/2019/8104-0021\$10.00 
are expected to last longer for reasons other than coalition involvement, positively biasing our estimate of the relationship. However, other states may only be willing to join more minor crises that are easier to resolve. This would result in coalitions being present in inherently shorter crises, negatively biasing our estimate of the relationship. If not addressed, a positive bias would cause us to overestimate the effect of a military coalition on crisis duration and a negative bias would cause us to underestimate the effect.

To address this inferential challenge, we develop a new statistical model that is an extension of instrumental variable estimation in survival analysis. The model estimates coalition formation and crisis duration jointly. This model explicitly incorporates the correlation between the two processes into our estimates, controlling for any bias generated by the coalition formation process. The results from our joint model provide strong support for the theoretical argument. An analysis of 255 post-World War II interstate crises demonstrates that, even after controlling for the endogeneity of coalitions, the involvement of a military coalition tends to extend the duration of crises by approximately 284 days.

This research proceeds as follows. In the next section, we discuss the role of military coalitions in crises. We then argue that the presence of a coalition can lengthen crises, and we explain how the endogeneity of coalition formation presents a challenge for evaluating the argument. Following that, we describe the research design we use to address the potential endogeneity and test our hypothesis. We then present our empirical results, and in the final section, we discuss the broad implications of our findings and provide several suggestions for future research.

\section{MILITARY COALITIONS AND FOREIGN POLICY CRISES}

In pursuit of political goals, states sometimes resort to military threats. Military threats can help to obtain valuable concessions from other states. Notably, these threats trigger international crises. A state involved in a crisis experiences a threat to one or more of its basic values and a heightened probability of involvement in military hostilities (Brecher and Wilkenfeld 1997). Crises do not necessarily result in war and often end without violence, as the Cuban Missile Crisis did in 1962. However, some crises, such as the July Crisis of 1914, are not resolved peacefully and can be accompanied by war. ${ }^{2}$

A key factor in determining whether a state achieves a favorable outcome in a crisis is its relative capabilities. If a

2. See Wolford (2014) for research on how coalitions affect the probability of crises escalating to war. crisis escalates to war, the side with greater military capabilities, all else equal, would be expected to have the crisis resolved in its favor. This is due to the side with greater capabilities being more likely to achieve military victory. However, even if the crisis never escalates to war, the side with greater military capabilities will be better able to achieve a more favorable outcome. This is because any negotiated outcome will be shaped by expectations of the result that would be produced by the outside option of war (e.g., Fearon 1995; Powell 1999). Thus, a state benefits from having its threats backed by more military capabilities.

Recognizing the important role relative military capabilities play in shaping crisis outcomes highlights the incentives states involved in crises have for forming military coalitions. A military coalition is a group of states that threaten to use force together against another state (or states). An obvious advantage of being part of a coalition is having additional military power available. In other words, states aggregate their capabilities through the formation of military coalitions. Given the impact of relative power on crisis outcomes, coalition formation, unsurprisingly, can help states obtain more favorable outcomes in crises. In fact, Morey (2016) demonstrates that for crises that escalate to war, coalitions are more likely to be victorious than states fighting outside a coalition.

Although coalition partners provide a state involved in a crisis clear benefits, their involvement comes at a cost. The coalition builder must compensate its partners for their cooperation in crisis bargaining and possible war (Wolford 2015). Compensation can involve modifying war aims, strategy adjustments, dividing the spoils of victory, or costly side payments. Thus, states deciding whether to enlist the help of coalition partners in a crisis face a trade-off between obtaining additional military power and making policy concessions to coalition partners. A growing body of research analyzes when states will make this trade-off and form coalitions in times of crisis (Kreps 2011; Pilster 2011; Wolford and Ritter 2016) as well as when other states will agree to join (Tago 2007, 2014). ${ }^{3}$

Although paying the price to enlist the help of a coalition partner can improve a state's chances of victory in a crisis, research suggests that the presence of coalition partners can create new political challenges if victory is achieved. More specifically, Wolford (2017) suggests that victorious coalitions face unique bargaining problems. Unlike unilateral victors, a victorious coalition must agree on a division of the new status quo and how it will be defended. This creates opportunities

3. A related body of research addresses the conditions that lead states to defect from coalitions (Choi 2012; Pilster, Böhmelt, and Tago 2015; Weisiger 2016). 
for the break down of post-conflict peace that are not present in the absence of a coalition.

In the next section, we build on the notion that coalitions introduce a new set of bargaining obstacles to a crisis. However, we argue that these obstacles are not unique to victorious coalitions negotiating a post-conflict peace. Coalitions can create bargaining obstacles during crises, lengthening their duration. The concern during the crisis is not necessarily that the coalition partners will turn on one another but that a peaceful settlement will be delayed, extending the costly contest and increasing the chances of violence erupting between the two sides. We begin the next section by explaining how peaceful settlements are reached in crisis and then how coalitions can extend this process through two mechanisms.

\section{MILITARY COALITIONS AND CRISIS DURATION}

During a crisis, states bargain under the threat of war. That is, states disagree over the division of some good, and at least one side threatens to wage war if its demands are not met. A crisis ends when a mutually agreed on division of the disputed good is located. Agreements that end crises are often accompanied by an event, such as a troop withdrawal or cease-fire, that marks the reduction in threat perceptions and conflictual activity to levels that existed before the crisis trigger (Brecher and Wilkenfeld 1997).

As discussed above, a coalition can help a state achieve a better outcome than if it acts alone. However, despite this discernible benefit of forming a coalition during a crisis, we argue that coalitions can severely complicate crisis bargaining and lengthen the duration states spend in potentially deadly crisis situations. More specifically, we argue that coalitions can cause the lengthening of crises through two interrelated processes. ${ }^{4}$

First, the presence of a coalition adds an additional stage of bargaining to the crisis. When crises involve only the primary disputants, the actors bargain directly with one another over the disputed good. However, disputants that are members of a coalition must also bargain with their coalition partner(s). In the absence of coalition partners, a disputant only needs to consider its own interests, but acting as part of a coalition requires a disputant to take into account the preferences of its partners. If a partner's demands are not met, it can simply refuse to participate in the coalition.

The bargaining that occurs among coalition members determines the terms of cooperation and, as a result, the price

\footnotetext{
4. While in many formal bargaining models the actors come to agreement without delay, Kennan and Wilson (1993) demonstrate that with uncertainty bargaining delays are possible. Given the inherent uncertainty in interstate crises, our argument is more in-line with incomplete information bargaining models that allow for bargaining delay.
}

a disputant pays for the assistance of a coalition. Intracoalitional bargaining typically revolves around developing a joint strategy for dealing with the adversary. Coalition members often have divergent preferences over the deals they are willing to accept from the other side, the level of escalation they are willing to tolerate, and the resources they are willing to contribute. Coming to agreement on a collective crisis strategy can take considerable time. For example, at the height of the Cold War during the 1958 crisis over the Berlin Deadline, it took the Western powers several rounds of negotiations to form a response to the Soviet's demand for the demilitarization of West Berlin. ${ }^{5}$ A similar process took place at the start of the post-Cold War period when the United States negotiated extensively through a variety of channels to build a large coalition that eventually coerced Iraq into withdrawing from Kuwait in $1991 .^{6}$

Second, beyond adding another bargaining stage, coalitions can complicate the bargaining process with the adversary. In crises without coalitions, the disputants spend time negotiating with one another and figuring out what deals would be acceptable to the other side. This process is often obstructed by information asymmetries and incentives the disputants have to misrepresent that information (e.g., Fearon 1995). Involving a coalition can magnify this obstacle to crisis bargaining. When a coalition is involved, the adversary has to determine the bargaining position of multiple actors and try to discern how those preferences will be aggregated into a coalitional position. In negotiations over the demilitarization of West Berlin, for example, Soviet leadership had to consider the interests of multiple opponents, the United States, France, Britain, and West Germany, and then discern how their preferences would be aggregated to form a collective response.

Navigating this more complex bargaining interaction takes additional time. Sorting through the positions of multiple opponents and the credibility of each requires more extensive information gathering and analysis than when faced with a single opponent. Moreover, the involvement of multiple opponents often generates multiple negotiation fronts. For example, after invading and occupying Kuwait, Iraqi President Saddam Hussein not only engaged in talks with Kuwait but also the United States, the USSR, Israel, Arab League members, and others. Creating these additional negotiation fronts works to extend the time it takes to locate a deal that is

5. See International Crisis Behavior (ICB) project (Brecher and Wilkenfeld 1997) Crisis 168 for more details.

6. See ICB Crisis 393 for more details. Also, see Kreps (2011) for examples of this phenomenon in a broader set of US-led coalitions in the post-Cold War period. 
acceptable to all parties and resolve the crisis. The discussion of these two interrelated processes leads to our central hypothesis:

Coalition Hypothesis. The involvement of a military coalition increases the duration of an interstate crisis.

Testing our hypothesis and estimating the effect of coalitions on crisis duration can provide a clearer picture of the trade-off states face when deciding whether to obtain coalition partners or act unilaterally in a crisis. However, estimating this relationship is not straightforward. There is a potential endogeneity issue with the presence of a military coalition. The process leading to the presence of a coalition in a crisis can bias our estimate of the relationship between coalition involvement and crisis duration.

Disputants will most likely pursue coalition partners in crises when they value the issue under contention highly, or, in other words, particularly intractable crises. This is because compensating coalition partners and coordinating with them is costly, which requires a large benefit, such as acquiring a highly valued good, to offset. As a result, coalitions will tend to be involved in crises in which the disputants are willing to bargain harder and hold out longer for a better deal. If this is the case, our estimate of the relationship between coalition involvement and crisis duration will be positively biased, making it more likely to find support for our hypothesis.

However, it is also possible that potential coalition partners try to avoid the difficult crises and prefer to get involved in the cases in which a solution is more feasible. In these cases, coalition builders may still pursue partners because working through a coalition can defer some of the costs and, often more importantly, provide legitimacy to their willingness to resort to war over the issue. ${ }^{7}$ If coalitions tend to form around these more manageable crises, it would negatively bias estimates of the hypothesized relationship, making it less likely to find support for our hypothesis.

Given the strong potential for bias, a valid test of our hypothesis must take into account all of the factors that influence both the involvement of a coalition and crisis duration. This task, however, is complicated by the fact that many of the factors that need to be controlled for are difficult to measure. To confront this challenge, we develop and use a new statistical model that is an extension of instrumental variable estimation in survival analysis. This model, along with the data analyzed, is described in detail in the next section.

7. See both Kreps (2011) and Tago (2007) on the ability of coalitions to provide legitimacy.

\section{RESEARCH DESIGN}

We analyze the duration of interstate crises spanning from 1946 to 2001 identified by the ICB project (Brecher and Wilkenfeld 1997). ${ }^{8}$ We focus on two-sided crises that involve at least two crisis actors disputing against one another. To test our coalition hypothesis, we adopt the crisis as the unit of observation; we compare crisis duration for crises with and without a military coalition, controlling for potential confounders. ${ }^{9}$

Crisis duration is defined as the number of days between the initiation and termination of a crisis. The ICB project considers the initiation of a crisis to occur when there is an event "which leads decision makers to perceive a threat to basic values, time pressure for response and a heightened probability of involvement in military hostilities" (Brecher et al. $2016,10)$. The termination date for a crisis is when the actors perceive relations to return to the precrisis norm. Primary sources such as speeches, memoirs, and diaries are used by ICB coders to identify these dates. Crisis duration in our sample ranges between 2 and 1,462 days. The distribution of crisis duration is skewed to the right; the mean of crisis duration is about 146 days, whereas the median is 70 days.

We identify military coalitions using the coding of Wolford (2015). ${ }^{10}$ He defines a military coalition as "a group of two or more states that makes a threat to use force together against another state (or states) in an international crisis" (14). The key part of this definition is that coalitions make threats of collective military action. ${ }^{11}$ In other words, coalitions are not simply actors that are on the same side in a crisis; there must be some evidence of military cooperation for a group of states to be considered a coalition. There are 255 crises in our sample, 54 of which (21\%) involve a coalition on at least one side.

One issue with the 54 crises that involve a military coalition is that for some of them a coalition is only involved for a part of the lifespan of the crisis. Therefore, we need to be careful to differentiate between cases in which a coalition forms and extends the duration of a crisis and those cases in which a coalition joins an ongoing crisis in its late stages. To facilitate this, we treat coalition involvement as a time-varying covariate and split each crisis into a noncoalition phase and a

8. We rely on the ICB version 12 data set available at https://sites.duke .edu/icbdata/ (last accessed on January 3, 2018).

9. Given our theoretical focus on crisis bargaining, we study ICB crises rather than the more common narrower focus on war duration (e.g., Bennett and Stam 1996).

10. See table 2.7 in Wolford (2015) for a list of the coded coalitions.

11. It is important to note that coalitions are different from formal military alliances; coalitions can be formed without an alliance, and not all allied states form military coalitions in times of crisis. 
coalition phase..$^{12}$ As a result, coalition involvement is constant during each crisis phase, and, for those phases with coalitions, crisis duration is only coded for the period after the coalition is involved. This allows us to ensure that it is the coalition extending the crisis and not long crises attracting coalitions.

To identify the parts of a crisis that involve a coalition, we rely on the ICB participation dates of the coalition members. Thus, a coalition is considered present when one side of the crisis is joined by a state that would qualify as a coalition partner as coded by Wolford (2015). ${ }^{13}$ Ideally we would like to know the dates coalition members started bargaining among themselves. However, these dates are not readily available and may be unknown for many cases because of incentives coalition partners have to conceal their deliberations. As a result, our test is a conservative one because some of our crisis phases coded as not involving a coalition will contain periods of intracoalition bargaining that we would expect to extend crisis duration.

For the 54 crises in which a military coalition is identified, it is present throughout the entire course of the crisis in $14(26 \%)$ of them. The remaining 40 crises with a coalition take three general forms. First, in $9(17 \%)$ crises, the coalition is present at the start of the crisis but drops out before the crisis terminates. Second, in 19 (35\%) of the crises, the coalition joins an ongoing crisis and stays until its end. Finally, in $12(22 \%)$ crises, the coalition joins an ongoing crisis and drops out before the crisis ends. This generates a sample of 307 crisis phase observations for 255 crises.

Figure 1 shows the observed distribution of crisis duration for all the crises (top panel), those without a coalition (middle panel), and those that involve a coalition at one point in their lifespan (bottom panel). Consistent with our coalition hypothesis, crisis duration has a higher mean for crises with a coalition (241 days) than for crises without a coalition (120 days). ${ }^{14}$ While this comparison provides preliminary support for our hypothesis, the remaining discussion explains how we attempt to isolate the impact of a coalition on crisis duration.

12. As is typically done in a standard duration analysis with time-varying covariates, we treat all nonterminal phases as right censored.

13. This means that there are some small discrepancies between Wolford's and our codings of military coalitions; Wolford's data set contains seven additional military coalitions in which none of the coalition members are included as a crisis actor in the ICB data set.

14. It is apparent from the histograms that there are two potential outliers, the Second Yugoslavian Crisis of 1992 and the Democratic Republic of Congo Crisis of 1998, with duration longer than 1,000 days. Additionally, both of these crises involved a coalition. Therefore, in a robustness check presented below, we drop these observations from our analysis. Our conclusions do not change when these two cases are excluded from the analysis.
To make a valid comparison of crisis phases with and without a military coalition, we need to control for potentially confounding factors that may influence both the presence of a coalition and crisis duration in evaluating our coalition hypothesis. We thus control for two observable variables that might be correlated with both crisis duration and coalition formation. The first factor we control for is involvement by an intergovernmental organization (IGO) in the crisis. A coalition may be more likely to be formed when the disputants are able to acquire an explicit backing from the international community through an IGO; at the same time, an IGO may be more likely to be involved in crises that are expected to escalate and last longer (Chiba and Fang 2014). To avoid a positive omitted variable bias, we create a dummy variable coded 1 if an IGO is involved in a crisis and 0 otherwise. The data are based on the information from the ICB data set (Brecher and Wilkenfeld 1997).

The other factor we control for is the degree of military disparity between the two sides. We expect crises to be shorter when one side has a clear military advantage over the other side. Importantly, military disparity will be positively related to our coalition variable when coalitions provide states with a military advantage and negatively related when coalitions balance the capabilities of the two sides. Therefore, it has the potential to be an important control variable. ${ }^{15}$ The measure is equal to the stronger side's military capability divided by the sum of all disputants military capabilities. ${ }^{16}$ Military capability is operationalized using the Composite Index of $\mathrm{Na}$ tional Capabilities score from the Correlates of War (COW) project (Singer, Bremer, and Stuckey 1972). This variable ranges between 0.5 (power parity) to 1 (power disparity).

In addition to these covariates, we include fixed effects that control for unit-level heterogeneities. We use the list of "protracted conflicts" from the ICB project to identify the unit for fixed-effect estimation. ${ }^{17}$ This list identifies a set of

15. Military disparity is a function of coalition, which suggests that this variable may well be treated as a posttreatment variable rather than a potential confounding variable. For this reason, we also estimate models for which it is excluded, and our conclusions do not change.

16. We also created an alternative operationalization of this variable that excludes the military capabilities of coalition partners. As we discuss below, we use this alternative measure in our joint model to predict coalition formation. As a robustness check, we also use the alternative measure instead of the one that includes the capabilities of coalition partners in the duration equation. Our conclusions do not change in this alternative specification.

17. In a robustness check, we employ an alternative strategy for dealing with crisis-level heterogeneity and control for the type of issue underlying the crisis. This is done via a set of dummy variables based on the ICB's coding of the principal issue area for the crisis actors. Our conclusions do not change when this alternative specification is used. 

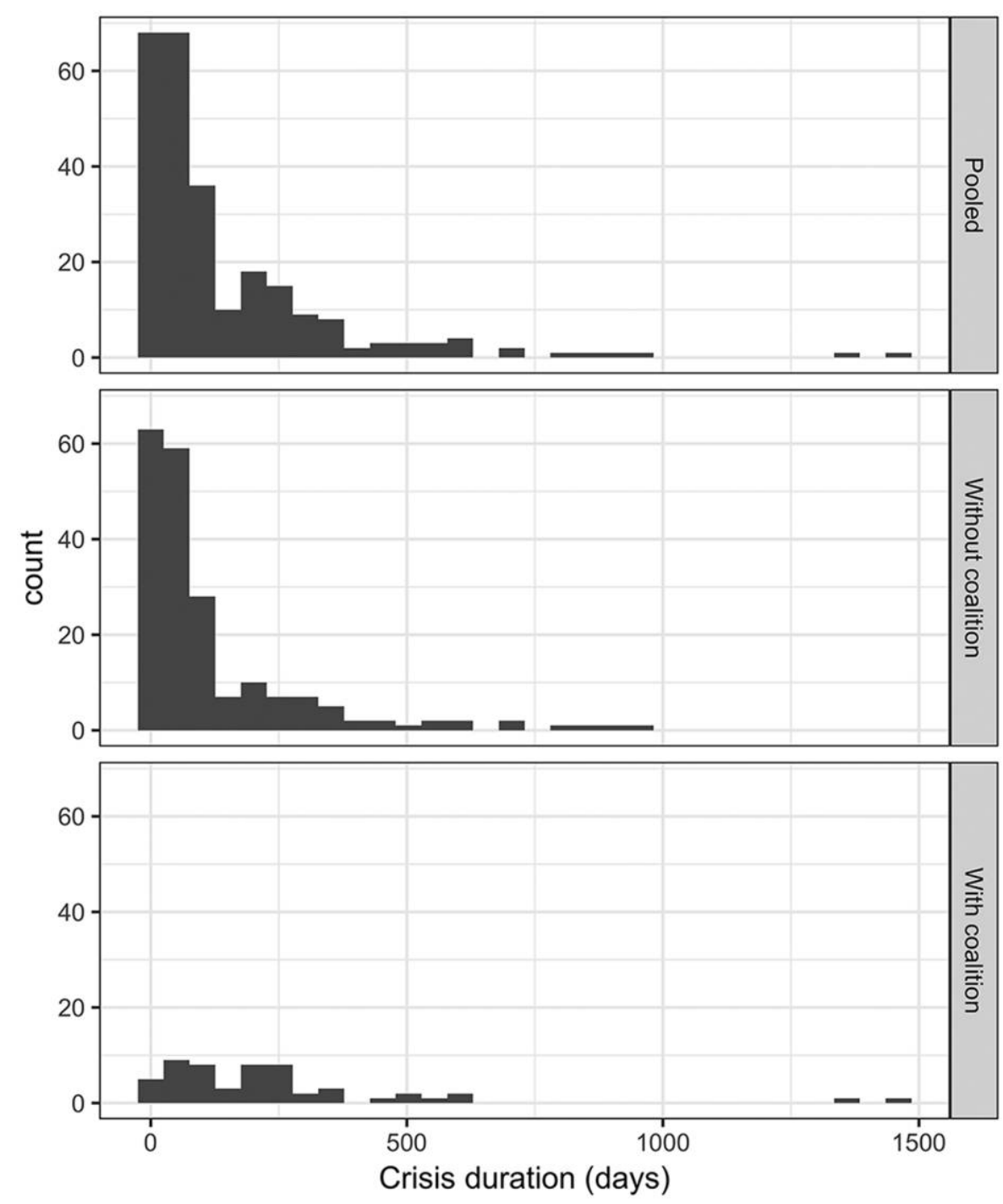

Figure 1. Histograms of observed crisis duration with and without a coalition

countries, regions, or country pairs that experience international crises repeatedly. In our data, $61 \%$ of crises occur within the context of one of 29 different protracted conflicts. ${ }^{18}$ Fixedeffect models allow us to make comparisons within each protracted conflict, controlling for factors specific to each of the protracted conflicts. In other words, we only compare Arab-

18. The list of protracted conflicts included in our data with the number of crises that occur in that conflict in parentheses is as follows: Angola (10), Chad-Libya (8), Ethiopia-Somalia (5), Rhodesia (11), Western Sahara (4), Zaire-Rwanda (2), Costa Rica-Nicaragua (2), Ecuador-Peru (3), HondurasNicaragua (5), Afghanistan-Pakistan (3), China-Vietnam (4), India-Pakistan (11), Indochina (5), Indonesia (4), Korea (2), North Korea Nuclear (1), Finland-Russia (1), Italy-Albania-Yugoslavia (1), Poland-Russia (2), Yugoslavia (3), Georgia-Russia (1), Arab-Israel (23), Iran-Iraq (3), Iraq-Kuwait (5), Yemen (3), East-West (20), Greece-Turkey (8), Taiwan Strait (4), and Iraq Regime (4).
Israeli crises to other Arab-Israeli crises rather than, for example, to Indo-Pakistani crises.

However, even after including the covariates and fixed effects described above, there may be unmeasured factors that limit our ability to draw valid inferences. As discussed in the previous section, difficult-to-measure factors, such as the tractability of a crisis, may influence both crisis duration and the presence of a coalition. If these factors are not controlled for, our estimates of the hypothesized relationship will be biased. Therefore, we construct a new statistical model that estimates coalition formation and crisis duration jointly, controlling for the correlation between unobservable factors that affect the two processes. ${ }^{19}$

19. The appendix contains the derivation of the model. 
The statistical model is an extension of instrumental variable regression models and shares some similarities with other multiequation duration models. ${ }^{20}$ The model incorporates an equation for coalition formation and another for crisis duration and allows the error terms for the two equations to be correlated. Moreover, the correlation coefficient allows us to test whether the unobservable factors that extend crisis duration make coalition formation more or less likely. If the unobservable factors make coalition formation more likely, the correlation coefficient will be positive and significant, and if they make it less likely, the correlation coefficient will be negative and significant. Estimating the model requires an assumption about the joint distribution of the correlation between the errors and an identification strategy. The distributional assumptions are discussed in the appendix, and our identification strategy is explained below.

To facilitate identification of the joint model, the equation for coalition formation should contain at least one independent variable that does not appear in the duration equation. Such identifier variables are expected to influence coalition formation, influence crisis duration indirectly through coalitions, but not influence crisis duration directly. The strategy we employ to identify our model stems from a large literature that emphasizes the importance of geography for conflict expansion. ${ }^{21}$ More specifically, we exploit the finding that states in close proximity to a conflict, especially contiguous ones, are more likely to intervene (e.g., Joyce, Ghosn, and Bayer 2014; Siverson and Starr 1990, 1991). It is argued that this is because geographic proximity increases the feasibility of military involvement for a state. States further away and separated by borders have more constraints on their ability to intervene in a dispute. In other words, in terms of Most and Starr's (1989) classic work, contiguous states are more likely to have the "opportunity" to participate in a military coalition. However, importantly for our analysis, once a state decides to get involved, the duration of the crisis will not be influenced by the geographic characteristics of the joiner. Both contiguous and noncontiguous coalitions engage in intracoalitional bargaining and complicate bargaining with the adversary.

20. See, e.g., Boehmke, Morey, and Shannon (2006) and Chiba, Martin, and Stevenson (2015). Whereas the duration models introduced in these two articles are designed to address selection bias, our model is designed to correct endogeneity. However, both sets of models are similar in that they employ a separate equation to explain either the initial selection or the endogenous regressor. For a discussion of a general statistical framework to construct multiequation models to facilitate causal inferences, see Braumoeller et al. (2018).

21. Our identification strategy closely follows one employed by Morey (2016) in an analysis of the impact of coalitions on interstate war outcomes.

To create our identifying variable we count the number of states contiguous to side one and the number contiguous to side two. We then use the maximum of these two counts. The idea being that whether the crisis experiences a coalition will be more heavily influenced by the side that has more neighbors. To code contiguity we use the COW Direct Contiguity data set (Stinnett et al. 2002). We estimate a model in which the coding of this variable is based solely on states that share a border and a model in which contiguity also includes those states separated by 400 miles of water or less.

For the duration equation of our statistical model, we adopt a parametric duration specification. We use model fit statistics to choose between three different parametric specifications of the underlying hazard. Specifically, we estimate Weibull, log normal, and log logistic models and choose the one that bests fits the data in terms of the Akaike information criterion.

\section{EMPIRICAL RESULTS}

Before presenting results from our new model, we first report results from single-equation duration models that do not jointly estimate coalition formation and crisis duration. These models allow us to gauge the importance of controlling for the endogeneity of coalition formation. The estimation results are presented in table 1 . All four of the models include protracted conflict-level fixed effects, although the estimated coefficients for the 30 fixed-effect terms are not shown for purposes of brevity. The coefficients for the independent variables are

Table 1. Duration Models of International Crises, 1946-2001

$(1)$

Coalition

IGO involvement

Military disparity

$\log (\sigma)$

Crisis phases

Crises

AIC

Note. All four models are based on the log normal specification. Positive coefficients are associated with longer duration. Estimates on fixed-effect parameters are omitted for brevity. Standard errors in parentheses. AIC $=$ Akaike information criterion; IGO = intergovernmental organization.

${ }^{*} p<.10$

${ }^{* *} p<.05$.

${ }^{* * *} p<.01$. 
shown in the accelerated failure time metric; positive estimates are associated with longer duration, and negative estimates are associated with shorter duration. As mentioned above, we estimate three different parametric duration models for each of the four combinations of independent variables to choose the best-fitting parametrization for the underlying risk of crisis termination. As it turns out, the log normal specification performs the best in all four models. The estimated $\sigma$ is approximately 1.2 across all four models, suggesting that the hazard rate rises to its peak quickly and then falls. ${ }^{22}$

We find consistent support for the coalition hypothesis from all four models; the estimated coefficient for the coalition variable is positive and statistically significant, whether we control for IGO involvement, military disparity, or both. To illustrate the substantive effect of a coalition on crisis duration, we calculate predicted mean duration for crises with and without a coalition based on the best-fitting model in table 1, model 4, holding constant the IGO involvement and military disparity variables at their median values ( 1 and 0.84 , respectively). The fixed-effect parameters are set at the values for crises that occur outside any protracted conflict.

Figure 2 plots the predicted crisis duration for the two scenarios. ${ }^{23}$ The predicted mean duration for crises without a coalition is about 128 days; the predicted crisis duration rises to 384 days when a crisis involves a coalition. The estimated impact of having a coalition on crisis duration is therefore 256 days with the $95 \%$ confidence interval of (114, 458). This represents a $200 \%$ increase in the estimated crisis duration. Thus, our single-equation models indicate that the presence of a coalition is having a large substantive impact on the duration of crises.

Although the models in table 1 provide support for the coalition hypothesis, they do not completely rule out our concerns of endogeneity. Therefore, table 2 reports estimation results from our joint models of coalition formation and crisis duration. The first part of the table reports estimated coefficients for variables included in the crisis duration equation, and the second part reports those included in the coalition formation equation. The third part of the table reports the estimated correlation coefficient for each model, which denotes the correlation between the errors in the two equations. As before, the protracted conflict fixed-effect coefficients are not reported for purposes of brevity. Model 5 is our main model, and models 6-8 provide important robustness checks.

22. Since $\sigma$ must be constrained to be positive, we estimate $\log (\sigma)$ instead. We can obtain the value of $\sigma$ by exponentiating the estimated logged $\sigma$.

23. For all figures, uncertainty estimates are obtained by following the procedure proposed by King, Tomz, and Wittenberg (2000).

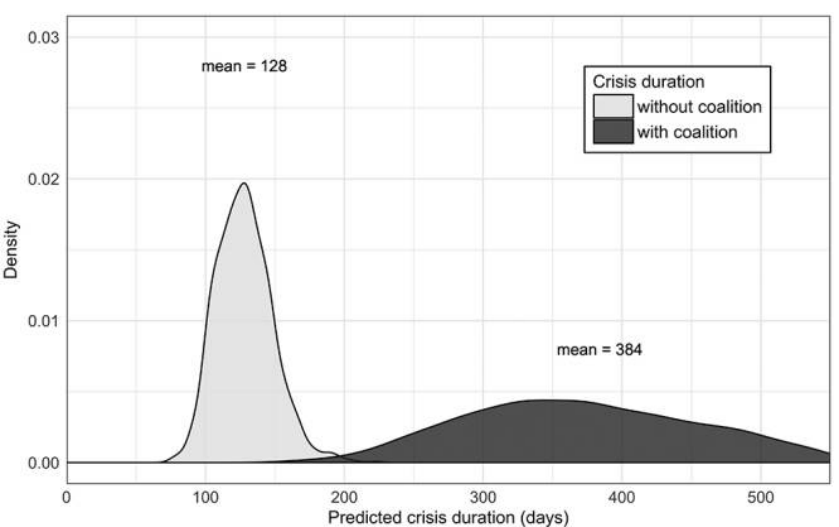

Figure 2. Impact of coalition on crisis duration from single-equation model. Predicted mean crisis duration for crises with and without a coalition based on the best-fitting model in table 1, model 4 . The two independent variables are held constant at their median value, and fixed-effect parameters are set at values for crises that occur outside a protracted conflict. Mean duration is calculated by numerically integrating the estimated survivor function.

The first piece of information to note from table 2 is that the estimated correlation parameter is negative and statistically significant across all four models. ${ }^{24}$ This indicates that our joint model is necessary to test our hypothesis and that unobserved factors were biasing the estimates from the singleequation models. Moreover, it suggests that unobservables that contribute to shorter crises also make coalition formation more likely. In other words, coalitions form during inherently shorter crises, negatively biasing our previous estimates.

Figure 3 plots the predicted crisis duration for the two scenarios based on our joint model. The predicted mean duration for crises without a coalition is about 12 days; the predicted crisis duration rises to 296 days when a crisis involves a coalition. The estimated impact of having a military coalition on crisis duration is therefore 284 days with the $95 \%$ confidence interval of $(163,488)$, approximately one month longer than the estimate obtained from the single-equation model. Moreover, the revised estimates indicate that the involvement of a coalition causes a 2,367\% increase in the estimated crisis duration, which is substantially larger than the percentage increase obtained from the single-equation model. Thus, failing to control for the endogeneity issue with our joint model underestimates the effect of a coalition on crisis duration. Our revised estimates suggest that a crisis without a coalition would last less than two weeks, but if that crisis were to involve a coalition it would be extended by more than 9 months. This finding indicates that soliciting the help of coalition partners can come at a significant cost for a state.

24. Since the correlation coefficient, $\rho$, must be between -1 and 1 , we estimate the inverse hyperbolic tangent of $\rho$. 
Table 2. Joint Models of Coalition Formation and Crisis Duration, 1946-2001

\begin{tabular}{|c|c|c|c|c|}
\hline & $\begin{array}{l}\text { Main } \\
(5)\end{array}$ & $\begin{array}{c}\text { Land Border } \\
\text { (6) }\end{array}$ & $\begin{array}{l}\text { Duration Outliers } \\
\text { (7) }\end{array}$ & $\begin{array}{c}\text { Coalition Outliers } \\
\text { (8) }\end{array}$ \\
\hline \multicolumn{5}{|l|}{ Crisis duration: } \\
\hline Coalition & $\begin{array}{l}3.364^{\star * *} \\
(.514)\end{array}$ & $\begin{array}{l}3.186^{\star * *} \\
(.606)\end{array}$ & $\begin{array}{l}3.370^{\star * *} \\
(.514)\end{array}$ & $\begin{array}{l}3.650^{\star * \star} \\
(.335)\end{array}$ \\
\hline IGO involvement & $\begin{array}{l}.108 \\
(.202)\end{array}$ & $\begin{array}{l}.139 \\
(.199)\end{array}$ & $\begin{array}{l}.103 \\
(.202)\end{array}$ & $\begin{array}{c}.093 \\
(.202)\end{array}$ \\
\hline Military disparity & $\begin{array}{c}-1.200^{* *} \\
(.603)\end{array}$ & $\begin{array}{r}-1.142^{\star} \\
(.611)\end{array}$ & $\begin{array}{c}-1.190^{* *} \\
(.604)\end{array}$ & $\begin{array}{r}-1.074^{\star} \\
(.596)\end{array}$ \\
\hline $\log (\sigma)$ & $\begin{array}{l}.312^{* * *} \\
(.069)\end{array}$ & $\begin{array}{l}.293^{* * *} \\
(.075)\end{array}$ & $\begin{array}{l}.313^{* * *} \\
(.069)\end{array}$ & $\begin{array}{l}.334^{* * *} \\
(.056)\end{array}$ \\
\hline \multicolumn{5}{|l|}{ Coalition formation: } \\
\hline IGO involvement & $\begin{array}{l}.787^{* * *} \\
(.274)\end{array}$ & $\begin{array}{l}.778^{* * *} \\
(.278)\end{array}$ & $\begin{array}{l}.796^{* * *} \\
(.274)\end{array}$ & $\begin{array}{l}.762^{\star * *} \\
(.262)\end{array}$ \\
\hline Military disparity (without coalition) & $\begin{array}{c}.547 \\
(.680)\end{array}$ & $\begin{array}{c}.630 \\
(.704)\end{array}$ & $\begin{array}{l}.533 \\
(.679)\end{array}$ & $\begin{array}{c}.567 \\
(.650)\end{array}$ \\
\hline Neighbors (land + sea) & $\begin{array}{l}.074^{* * *} \\
(.022)\end{array}$ & & $\begin{array}{l}.075^{\star * *} \\
(.022)\end{array}$ & $\begin{array}{l}.075^{\star * *} \\
(.021)\end{array}$ \\
\hline Neighbors (land) & & $\begin{array}{l}.115^{* * *} \\
(.037)\end{array}$ & & \\
\hline Constant & $\begin{array}{c}-3.049^{* * *} \\
(.682)\end{array}$ & $\begin{array}{c}-3.127^{* * *} \\
(.707)\end{array}$ & $\begin{array}{c}-3.040^{* * *} \\
(.681)\end{array}$ & $\begin{array}{c}-3.100^{* * *} \\
(.665)\end{array}$ \\
\hline Correlation $(\rho)$ & $\begin{array}{l}-.842^{\star * *} \\
(.114)\end{array}$ & $\begin{array}{l}-.793^{\star \star \star} \\
(.156)\end{array}$ & $\begin{array}{l}-.843^{\star * \star} \\
(.114)\end{array}$ & $\begin{array}{l}-.913^{\star * *} \\
(.049)\end{array}$ \\
\hline Crisis phases & 307 & 307 & 305 & 305 \\
\hline Crises & 255 & 255 & 253 & 253 \\
\hline AIC & $3,150.9$ & $3,151.0$ & $3,150.2$ & $3,110.4$ \\
\hline
\end{tabular}

Note. All four models are based on the log normal specification. Positive coefficients in the crisis duration equation are associated with longer duration. Estimates on fixed-effect parameters included in the duration equation are omitted for brevity. Standard errors in parentheses. AIC $=$ Akaike information criterion; IGO $=$ intergovernmental organization.

${ }^{*} p<.10$.

${ }^{* *} p<.05$.

${ }^{* * *} p<.01$.

In addition to our main model, table 2 presents several notable modifications to our joint model. First, we examine the robustness of our result to a reasonable alternative coding of our identifying variable. More specifically, model $6 \mathrm{dem}$ onstrates that the result holds even when we restrict neighbors to those states sharing a border. Second, as mentioned in footnote 14, we drop the two crises in which the duration is longer than 1,000 days, the 1992 Second Yugoslavian Crisis and the 1998 Democratic Republic of Congo Crisis, both of which involve a coalition. Model 7 indicates that these cases are not driving our results. Finally, we drop two cases that have an exceptional number of coalition members. Both the 1990 Gulf War and the 1999 Kosovo crisis involved 11 coalition members, and the next largest coalition in the data has 5 coalition members. Model 8 demonstrates that the result does not depend on the inclusion of these two cases.
Unlike the single-equation models in table 1, the joint models presented in table 2 provide information about the determinants of coalition formation. Importantly, the estimates show that the number of surrounding neighbors significantly increases the probability of coalition formation. This is consistent with our expectations and provides a key piece of evidence in support of our identification strategy. With regard to the other variables, IGO involvement increases the probability of a coalition forming but has no effect on crisis duration. Thus, it is possible that the only effect IGO involvement has on crisis duration is through the encouragement of coalition formation. Military disparity seems to have no effect on coalition formation, but it consistently shortens crisis duration.

The purpose of our joint model is to control for unmeasured factors related to both crisis duration and coalition 


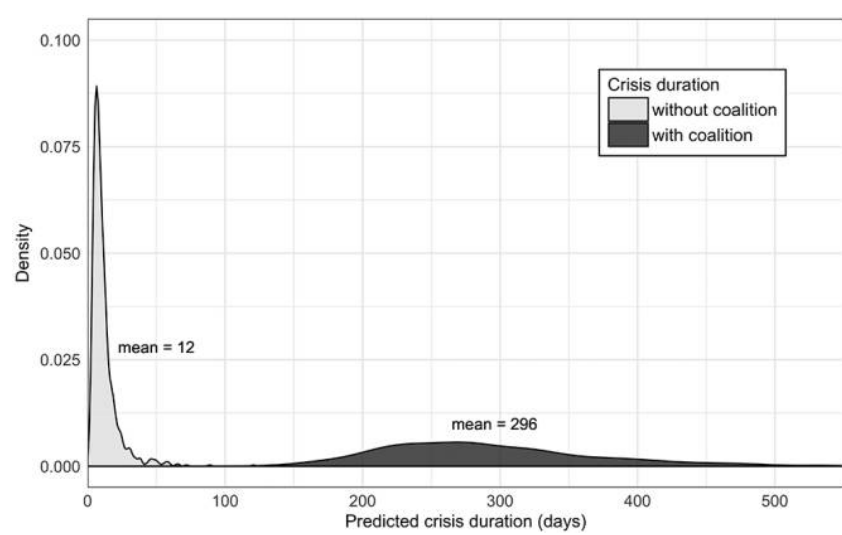

Figure 3. Impact of coalition on crisis duration from joint model. Predicted mean crisis duration for crises with and without a coalition based on our main model, model 5 . The other independent variables are held constant at their median value, and fixed-effect parameters are set at values for crises that occur outside a protracted conflict.

formation. However, our joint model ignores the process by which states select into crises. Given that previous research suggests initiators select crises strategically on the basis of whether a target will receive support, we want to ensure that the sample selection process is not biasing our estimates (Gartner and Siverson 1996; Werner 2000). Therefore, as a robustness check, we test our hypothesis employing a sample selection model, model 9 in table 3 . This model is similar to the one developed by Boehmke et al. (2006), but our model allows for more flexibility in the correlation coefficient. ${ }^{25}$

We estimate the model using a sample of all dyad years. ${ }^{26}$ The dependent variable for the selection equation codes whether the dyad experiences an ICB crisis in a given year. Variables that capture the likelihood of two states having a dispute, such as distance, contiguity, and similarity of interests between the potential disputants based on UN voting, are included in the selection equation and used to identify the model. ${ }^{27}$ The results from this model also provide support for the hypothesis. Moreover, the correlation parameter for this model is insignificant, indicating that the crisis selection process can be safely ignored for our analysis.

The final set of analyses we conduct disaggregate the coalitions in our sample to consider whether certain types of military coalitions experience longer crises than others. One natural extension of our argument is that larger coalitions

25. The derivation of the statistical model is included in the replication materials.

26. Dyad-year observations are created based on the COW project's state system membership list (version 2016), available at http://correlatesofwar.org (last accessed on January 3,2018). We drop six ICB crises that involve a nonCOW member state.

27. Variables for the selection model were obtained using the NewGene software (Bennett, Poast, and Stam 2017). may extend crisis duration more than smaller coalitions. This is because increasing the number of coalition members may exacerbate the bargaining problems described above. To test this possibility, model 10 in table 3 replaces our coalition

Table 3. Supplementary Models of International Crises, 1946-2001
Crisis duration:
Coalition

Coalition size (logged)

Only one major power in coalition

Other coalition

IGO involvement

Military disparity

$\log (\sigma)$

Crisis involvement:

Military disparity

Distance

Contiguity

Interest similarity

Peace years

Peace years ${ }^{2}$

Peace years ${ }^{3}$

Constant

Correlation $(\rho)$

Dyad years

Crisis phases

Crises

AIC
(9)

(10)

(11) $1.092^{* * *}$

(.233)

$.946^{* * *}$

(.359)

$1.244^{* * *}$

(.326)

$.325^{*}$

(.177)

(.179)

$-.784$

(.615)

$.190^{* * *}$

(.046)

(.176)

$-1.048^{*}$

$-.961^{\star}$

(.578)

$.181^{* \star *} \quad .181^{\star * \star}$

$(.044)$

Note. All three models are based on the log normal specification. Positive coefficients in the crisis duration equation are associated with longer duration. Estimates on fixed-effect parameters included in the duration equation are omitted for brevity. Standard errors in parentheses. AIC = Akaike information criterion; IGO = intergovernmental organization.

$* p<.10$.

${ }^{* *} p<.05$.

$* * * p<.01$. 
dummy variable with a logged count of the number of coalition members. The results suggest that increasing the size of a coalition extends the duration of the crisis. Thus, when states strengthen their coalition through the inclusion of new members, they are also extending the duration of the crisis. More specifically, increasing the size of a coalition from two to three members, extends the duration of a crisis by approximately 80 days with the $95 \%$ confidence interval of $(28,156)$.

One possible strategy for minimizing the obstacles a coalition creates is by forming the coalition around a single major power. Given that the major power will have the most capabilities and be essential to the success of the coalition, the other members may defer to the major power's bargaining stance, simplifying the bargaining. To test this possibility, model 11 in table 3 includes two coalition variables, one coding those that involve a single major power and one capturing all other coalitions. The results indicate that both types of coalitions extend the duration of crises, and the effect is slightly smaller for single major power coalitions, but the difference is not significant. Therefore, it seems that even single major power coalitions generate considerable bargaining obstacles that extend crises. One possible explanation for this lack of difference between the two types of coalitions is that minor powers that get included in coalitions are important enough to their coalition's success that their preferences get considered in intracoalition bargaining and by the other side.

Future research should continue to consider whether certain types of coalitions experience shorter crises than other coalitions. It is possible that forming a coalition among states with similar preferences or that have an existing alliance agreement may alleviate some of the bargaining obstacles a coalition introduces to a crisis. Analyses along these lines will provide policy makers choosing among a set of possible coalition partners a more nuanced understanding of the implications of any given choice.

\section{CONCLUSION}

Our research highlights an often overlooked cost of military coalition participation. Introducing a coalition to a crisis can lengthen the crisis and extend the time disputants spend bargaining under the threat of war. This finding provides a clearer picture to policy makers of the trade-offs associated with achieving foreign policy goals through a coalition. However, in addition to providing useful insights for policy makers, our findings have broad implications for several areas of study.

First, our findings contribute to a growing body of research on bargaining delays. Whereas our focus is on bargaining delays in interstate crises, previous studies examine bargaining delays, for example, in civil wars (Cunningham 2006) and cabinet formation in parliamentary democracies (Golder 2010; Martin and Vanberg 2003). Similar to our findings, these studies demonstrate that increases in the number of relevant actors extend the duration of bargaining. Thus, when taken together, these seemingly disparate areas of research converge on a more general finding. Future research should seek to identify the broader conditions under which the involvement of an additional actor contributes to bargaining delay.

Second, our research highlights the importance of intracoalition bargaining. An extensive body of research in international relations examines various aspects of the bargaining that occurs between adversaries, but our understanding of bargaining among actors on the same side of a dispute is less developed. Developing an understanding of intracoalition bargaining is key to understanding when coalitions will form and the price states pay to obtain partners. Recent research on alliances has made some progress in this area, but this work has the benefit of relying on alliance treaties to extract information about the bargained outcomes among partners (Johnson 2015). Thus, a systematic analysis of bargained outcomes reached among coalition partners would entail original data collection but would be a worthwhile effort that would significantly advance research on the politics of military coalitions.

Finally, the impact of the coalition formation process on our empirical analysis suggests the need for greater attention to endogenous regressors in international relations research. A significant body of work in international relations highlights the importance of accounting for sample selection and strategies for doing so (e.g., Boehmke et al. 2006; Reed 2000; Sartori 2003), but the topic of endogenous regressors has received considerably less attention. Our joint model offers one possible strategy for dealing with this inferential challenge and will, hopefully, prove useful for others addressing this issue in their research.

\section{ACKNOWLEDGMENTS}

The authors would like to offer a special thanks to Scott Wolford for sharing his data with us and answering any questions we had as well as commenting on an early draft. We also thank Tiffany Barnes, Kyle Beardsley, Songying Fang, Pat James, Ashley Leeds, Dan Morey, Jim Morrow, Aris Perperoglou, Marius Radean, Clayton Thyne, and Justin Wedeking for helpful comments and suggestions. Finally, we thank our three anonymous reviewers whose reviews greatly improved the project.

\section{APPENDIX}

We derive a statistical model that estimates the probability of coalition formation and crisis duration jointly and thereby addresses the endogeneity of coalition formation. For each international crisis phase $i=1, \ldots, n$, we define a latent random variable $c_{i}^{*}$ to represent the disputants' propensity to 
form a coalition. We allow $c_{i}^{\star}$ to be a function of covariates $z_{i}$ and their coefficients $\gamma$, such that

$$
c_{i}^{*}=z_{i} \gamma+\varepsilon_{i},
$$

where $\varepsilon_{i}$ is an error term with a symmetric distribution characterized by a cumulative distribution function $F_{\varepsilon}(\cdot)$. We do not observe the value of $c_{i}^{*}$ directly; instead we observe $c_{i}=1$ (a coalition is formed) when $c_{i}^{*}>0$ and $c_{i}=0$ (a coalition is not formed) when $c_{i}^{*} \leq 0$. In addition, we define another random variable $t_{i}^{*}$ that represents the latent duration for crisis phase $i$, such that

$$
\log \left(t_{i}^{*}\right)=\beta c_{i}+\boldsymbol{x}_{i} \boldsymbol{\delta}+\alpha^{-1} \eta_{i},
$$

where $\beta$ captures the effect of $c_{i}$ on the duration of crisis phase, $\boldsymbol{x}_{\boldsymbol{i}}$ is a vector of covariates, $\boldsymbol{\delta}$ is a vector of coefficients, and $\eta_{i}$ is an error term with a cumulative distribution function $F_{\eta}(\cdot)$ and density function $f_{\eta}(\cdot)$, scaled by $\alpha$.

However, univariate estimation of equation (A2) may not give us an unbiased estimate of $\beta$ if some unobservable factors influence $c_{i}^{*}$ and $t_{i}^{*}$ simultaneously, resulting in a correlation between $\varepsilon_{i}$ and $\eta_{i}$. For example, suppose a coalition is more likely to be formed in more "intractable" crises that tend to last longer. This implies that $\varepsilon_{i}$ and $\eta_{i}$ will be positively correlated. Then, when $\varepsilon_{i}$ takes an unusually high value, $\eta_{i}$ will on average take an unusually high value. Unless we account for the correlation between the two terms, we will overestimate $\beta$, because part of the effect of $\eta_{i}$ on $t_{i}^{*}$ will be picked up by $\beta$. In other words, we will incorrectly attribute to $\beta$ the effect of any part of $\eta_{i}$ that is correlated with $\varepsilon_{i}$.

To obtain an unbiased estimate of $\beta$, we thus need a statistical model that estimates equations (A1) and (A2) jointly while controlling for the correlation between $\varepsilon_{i}$ and $\eta_{i}$. The likelihood function for such a statistical model takes the following form:

$$
\begin{gathered}
L=\prod_{i=1}^{n} \operatorname{Pr}\left(t_{i}^{*}=t_{i} \cap c_{i}^{*}>0\right)^{c_{i}\left(1-d_{i}\right)} \operatorname{Pr}\left(t_{i}^{*}=t_{i} \cap c_{i}^{\star} \leq 0\right)^{\left(1-c_{i}\right)\left(1-d_{i}\right)} \\
\operatorname{Pr}\left(t_{i}^{*}>t_{i} \cap c_{i}^{*}>0\right)^{c_{i} d_{i}} \operatorname{Pr}\left(t_{i}^{*}>t_{i} \cap c_{i}^{*} \leq 0\right)^{\left(1-c_{i}\right) d_{i}},
\end{gathered}
$$

where $t_{i}$ is the observed duration of a crisis phase and $d_{i}$ is the censoring indicator coded 1 for censored crisis phases and 0 otherwise. To specify this likelihood function, we need to characterize a joint distribution of $t_{i}^{*}$ and $c_{i}^{*}$. Since $t$ is duration and $c$ is binary, specifying the joint distribution of the two is not straightforward. We use a copula function to bind together the two univariate probability distributions $F_{\varepsilon}(\cdot)$ and $F_{\eta}(\cdot)$ to produce a bivariate probability distribution. ${ }^{28}$ Spe-

28. For applications of copula functions in political science, see Chiba, Martin, et al. (2015), Chiba, Metternich, and Ward (2015), and Fukumoto (2015). cifically, for two random variables $x_{1}^{*}$ and $x_{2}^{\star}$ with associated univariate distribution functions $F_{1}(\cdot)$ and $F_{2}(\cdot)$, the bivariate distribution can be characterized as $F_{12}\left(x_{1}, x_{2}\right)=\operatorname{Pr}\left(x_{1}^{\star}<\right.$ $\left.x_{1} \cap x_{2}^{\star}<x_{2}\right)=C\left(F_{1}\left(x_{1}\right), F_{2}\left(x_{2}\right) ; \theta\right)$, where $C(\cdot, ; \theta)$ is a bivariate copula function, and $\theta$ is a parameter that measures the degree of association between $x_{1}^{\star}$ and $x_{2}^{\star}$.

The first component of (A3), the joint probability that a coalition is formed and the crisis phase lasted for duration $t_{i}$, is obtained by applying Bayes's rule and taking the derivatives of the joint distributions, as follows:

$$
\begin{gathered}
\operatorname{Pr}\left(t_{i}^{\star}=t_{i} \cap c_{i}^{*}>0\right)=\operatorname{Pr}\left(c_{i}^{*}>0 \mid t_{i}^{*}=t_{i}\right) \times \operatorname{Pr}\left(t_{i}^{*}=t_{i}\right) \\
=\operatorname{Pr}\left(\varepsilon_{i} \leq z_{i} \gamma \mid t_{i}^{*}=t_{i}\right) \times f_{\eta}\left(t_{i}\right) \\
=\frac{\partial C\left(F_{\varepsilon}\left(z_{i} \gamma\right), F_{\eta}\left(t_{i}\right) ; \theta\right)}{\partial F_{\eta}\left(t_{i}\right)} \times f_{\eta}\left(t_{i}\right) \\
=C_{\varepsilon \mid \eta}\left(F_{\varepsilon}\left(z_{i} \gamma\right), F_{\eta}\left(t_{i}\right) ; \theta\right) \times f_{\eta}\left(t_{i}\right),
\end{gathered}
$$

where $C_{a \mid b}(x, y ; \theta)$ is called a conditional copula that gives $\operatorname{Pr}(a<x \mid b=y)$. The second component of (A3), the joint probability that a coalition is not formed and the crisis lasted for duration $t_{i}$, is obtained simply by

$$
\begin{aligned}
\operatorname{Pr}\left(t_{i}^{*}\right. & \left.=t_{i} \cap c_{i}^{*} \leq 0\right)=\operatorname{Pr}\left(t_{i}^{*}=t_{i}\right)-\operatorname{Pr}\left(t_{i}^{*}=t_{i} \cap c_{i}^{*}>0\right) \\
& =f_{\eta}\left(t_{i}\right)-C_{\varepsilon \mid \eta}\left(F_{\varepsilon}\left(z_{i} \gamma\right), F_{\eta}\left(t_{i}\right) ; \theta\right) \times f_{\eta}\left(t_{i}\right) .
\end{aligned}
$$

The third component of (A3), the joint probability that a coalition is formed and the crisis phase is censored at duration $t_{i}$, is

$$
\begin{gathered}
\operatorname{Pr}\left(t_{i}^{*}>t_{i} \cap c_{i}^{*}>0\right)=\operatorname{Pr}\left(t_{i}^{*}>t_{i} \cap \varepsilon_{i} \leq z_{i} \gamma\right) \\
=\operatorname{Pr}\left(\varepsilon_{i} \leq z_{i} \gamma\right)-\operatorname{Pr}\left(t_{i}^{*} \leq t_{i} \cap \varepsilon_{i} \leq z_{i} \gamma\right) \\
=F_{\varepsilon}\left(z_{i} \gamma\right)-C\left(F_{\eta}\left(t_{i}\right), F_{\varepsilon}\left(z_{i} \gamma\right) ;-\theta\right) \\
=C\left(1-F_{\eta}\left(t_{i}\right), F_{\varepsilon}\left(z_{i} \gamma\right) ; \theta\right) .
\end{gathered}
$$

Finally, the last component of (A3), the joint probability that a coalition is not formed and the crisis phase is censored at duration $t_{i}$, is

$$
\begin{gathered}
\operatorname{Pr}\left(t_{i}^{*}>t_{i} \cap c_{i}^{*} \leq 0\right)=\operatorname{Pr}\left(t_{i}^{*}>t_{i}\right)-\operatorname{Pr}\left(t_{i}^{*}>t_{i} \cap c_{i}^{*}>0\right) \\
\quad=1-F_{\eta}\left(t_{i}\right)-C\left(1-F_{\eta}\left(t_{i}\right), F_{\varepsilon}\left(z_{i} \gamma\right) ; \theta\right) .
\end{gathered}
$$

From among several different copula functions that can be assigned to $C(\cdot, \cdot ; \theta)$, we choose the Gaussian copula because of its flexibility. It captures the association between 
the two random variables via a correlation coefficient $\rho$, which ranges between -1 (perfect negative correlation) and 1 (perfect positive correlation). A positive estimate of $\rho$ would indicate that a coalition is more likely to be formed in crises that tend to last longer, and a negative estimate would indicate that a coalition is less likely to be formed in crises that tend to last longer. More importantly, the model enables us to test our hypothesis on the effect of coalitions on crisis duration, controlling for the endogeneity of coalition formation. We assign Weibull, log normal, and log logistic distributions to $F_{\eta}(\cdot)$, and choose the one that fits the data better. We assign a standard normal distribution to $F_{\varepsilon}(\cdot)$ throughout the estimation.

\section{REFERENCES}

Bennett, D. Scott, Paul Poast, and Allan C. Stam III. 2017. "NewGene: A Conceptual Manual.” SSRN. doi:10.2139/ssrn.2596297.

Bennett, D. Scott, and Allan C. Stam III. 1996. "The Duration of Interstate Wars, 1816-1985." American Political Science Review 90 (2): 23957.

Boehmke, Frederick J., Daniel S. Morey, and Megan Shannon. 2006. "Selection Bias and Continuous-Time Duration Models: Consequences and a Proposed Solution." American Journal of Political Science 50 (1): 192-207.

Braumoeller, Bear F., Giampiero Marra, Rosalba Radice, and Aisha E. Bradshaw. 2018. "Flexible Causal Inference for Political Science." $\underline{\text { Political }}$ Analysis 26 (1): 54-71.

Brecher, Michael, and Jonathan Wilkenfeld. 1997. A Study of Crisis. Ann Arbor: University of Michigan Press.

Brecher, Michael, Jonathan Wilkenfeld, Kyle Beardsley, Patrick James, and David Quinn. 2016. International Crisis Behavior Data Codebook, version 11. http://sites.duke.edu/icbdata/data-collections/.

Chiba, Daina, and Songying Fang. 2014. "Institutional Opposition, Regime Accountability, and International Conflict." Lournal of Politics 76 (3): 798-813.

Chiba, Daina, Lanny W. Martin, and Randolph T. Stevenson. 2015. "A Copula Approach to the Problem of Selection Bias in Models of Government Survival." Political Analysis 23 (1): 42-58.

Chiba, Daina, Nils W. Metternich, and Michael D. Ward. 2015. "Every Story Has a Beginning, Middle, and an End (But Not Always in That Order): Predicting Duration Dynamics in a Unified Framework." Political Science Research and Methods 3 (3): 515-41.

Choi, Ajin. 2012. "Fighting to the Finish: Democracy and Commitment in Coalition War." Security Studies 21 (4): 624-53.

Cunningham, David E. 2006. "Veto Players and Civil War Duration." American Journal of Political Science 50 (4): 875-92.

DeRouen, Karl R., Jr., and Shaun Goldfinch. 2005. "Putting the Numbers to Work: Implications for Violence Prevention." Journal of Peace Research 42 (1): $27-45$.

Fearon, James D. 1995. "Rationalist Explanations for War." International Organization 49 (3): 379-414.

Fukumoto, Kentaro. 2015. "What Happens Depends on When It Happens: Copula-Based Ordered Event History Analysis of Civil War Duration and Outcome." Lournal of the American Statistical Association 110 (509): 83-92.

Gartner, Scott Sigmund, and Randolph M. Siverson. 1996. "War Expansion and War Outcome." Journal of Conflict Resolution 40 (1): 4-15.
Golder, Sona N. 2010. "Bargaining Delays in the Government Formation Process." Comparative Political Studies 43 (1): 3-32.

Hoffmann, Manuel, and Matthias Neuenkirch. 2017. "The Pro-Russian Conflict and Its Impact on Stock Returns in Russia and the Ukraine." International Economics and Economic Policy 14 (1): 61-73.

Johnson, Jesse C. 2015. "The Cost of Security: Foreign Policy Concessions and Military Alliances." Lournal of Peace Research 52 (5): 665-79.

Joyce, Kyle A., Faten Ghosn, and Reşat Bayer. 2014. "When and Whom to Join: The Expansion of Ongoing Violent Interstate Conflicts." British Journal of Political Science 44 (1): 205-38.

Kennan, John, and Robert Wilson. 1993. "Bargaining with Private Information." Journal of Economic Literature 31 (1): 45-104.

King, Gary, Michael Tomz, and Jason Wittenberg. 2000. "Making the Most of Statistical Analyses: Improving Interpretation and Presentation." American Journal of Political Science 44 (2): 341-55.

Kreps, Sarah E. 2011. Coalitions of Convenience: United States Military Interventions after the Cold War. New York: Oxford University Press.

Martin, Lanny W., and Georg Vanberg. 2003. "Wasting Time? The Impact of Ideology and Size on Delay in Coalition Formation." British Journal of Political Science 33 (2): 323-32.

Morey, Daniel S. 2016. "Military Coalitions and the Outcome of Interstate Wars." Foreign Policy Analysis 12 (4): 533-51.

Most, Benjamin A., and Harvey Starr. 1989. Inquiry, Logic, and International Politics. Columbia: University of South Carolina Press.

Pilster, Ulrich. 2011. "Are Democracies the Better Allies? The Impact of Regime Type on Military Coalition Operations." International Interactions 37 (1): 55-85.

Pilster, Ulrich, Tobias Böhmelt, and Atsushi Tago. 2015. "Political Leadership Changes and the Withdrawal from Military Coalition Operations, 1946-2001." International Studies Perspectives 16 (4): 463-83.

Powell, Robert. 1999. In the Shadow of Power: States and Strategies in International Politics. Princeton, NJ: Princeton University Press.

Reed, William. 2000. "A Unified Statistical Model of Conflict Onset and Escalation.” American Journal of Political Science 44 (1): 84-93.

Rigobon, Roberto, and Brian Sack. 2005. "The Effects of War Risk on US Financial Markets." Journal of Banking and Finance 29 (7): 176989.

Sartori, Anne E. 2003. "An Estimator for Some Binary-Outcome Selection Models without Exclusion Restrictions." Political Analysis 11 (2): $111-38$.

Singer, J. David, Stuart Bremer, and John Stuckey. 1972. "Capability Distribution, Uncertainty, and Major Power War, 1820-1965." In B. Russett, ed., Peace, War, and Numbers. Beverly Hills, CA: Sage, 19-48.

Siverson, Randolph M., and Harvey Starr. 1990. "Opportunity, Willingness, and the Diffusion of War." American Political Science Review 84 (1): 4767.

Siverson, Randolph M., and Harvey Starr. 1991. The Diffusion of War: A Study of Opportunity and Willingness. Ann Arbor: University of Michigan Press.

Stinnett, Douglas M., Jaroslav Tir, Paul F. Diehl, Philip Schafer, and Charles Gochman. 2002. "The Correlates of War (COW) Project Direct Contiguity Data, Version 3.0." Conflict Management and Peace Science 19 (2): 59-67.

Tago, Atsushi. 2007. "Why Do States Join US-Led Military Coalitions? The Compulsion of the Coalition's Missions and Legitimacy." International Relations of the Asia-Pacific 7 (2): 179-202.

Tago, Atsushi. 2014. "Too Many Problems at Home to Help You: Domestic Disincentives for Military Coalition Participation." International Area Studies Review 17 (3): 262-78.

Weisiger, Alex. 2016. "Exiting the Coalition: When Do States Abandon Coalition Partners during War?" International Studies Quarterly 60 (4): 753-65. 
Werner, Suzanne. 2000. "Deterring Intervention: The Stakes of War and Third-Party Involvement." American Journal of Political Science 44 (4): $720-32$.

Wolford, Scott. 2014. "Showing Restraint, Signaling Resolve: Coalitions, Cooperation, and Crisis Bargaining." American Journal of Political Science 58 (1): $144-56$

Wolford, Scott. 2015. The Politics of Military Coalitions. New York: Cambridge University Press.
Wolford, Scott. 2017. "The Problem of Shared Victory: War-Winning Coalitions and Postwar Peace." Lournal of Politics 79 (2): 702-16.

Wolford, Scott, and Emily Hencken Ritter. 2016. "National Leaders, Political Security, and the Formation of Military Coalitions." International Studies Quarterly 60 (3): 540-51.

Zussman, Asaf, Noam Zussman, and Morten Ørregaard Nielsen. 2008. "Asset Market Perspectives on the Israeli-Palestinian Conflict." Economica 75 (297): 84-115. 


\section{Corrigendum}

In footnote 20 of their article "Military Coalitions and Crisis Duration" (Journal of Politics 81, no. 4 [2019]: 1466-79), Daina Chiba and Jesse C. Johnson compare their estimator to two other existing multi-equation duration models developed by Boehmke, Morey, and Shannon (2006) and Chiba, Martin, and Stevenson (2015) and point out that their estimator differs from existing models. They should have, however, acknowledged that Boehmke's (2006) estimator is the closest to theirs. The authors were unfortunately unaware of Boehmke's (2006) estimator when they developed theirs. His application is a seemingly unrelated regression and theirs is an instrumentalvariable regression, but the underlying estimators are essentially the same. The primary difference is that Chiba and Johnson's model is derived as a special case within a flexible copula framework that allows them to specify and estimate models with different distributional assumptions. For example, in ad- dition to the probit-log normal model that was developed in Boehmke (2006), Chiba and Johnson derived and estimated probit-Weibull and probit-log logistic specifications to choose the best-fitting model. This is consistent with one of the suggested directions for future research proposed by Boehmke (2006, 437).

\section{REFERENCES}

Boehmke, Frederick J. 2006. "The Influence of Unobserved Factors on Position Timing and Content in the NAFTA Vote." Political Analvsis 14 (4): 421-38.

Boehmke, Frederick J., Daniel S. Morey, and Megan Shannon. 2006. “Selection Bias and Continuous-Time Duration Models: Consequences and a Proposed Solution." American Journal of Political Science 50 (1): 192-207.

Chiba, Daina, Lanny W. Martin, and Randolph T. Stevenson. 2015. “A Copula Approach to the Problem of Selection Bias in Models of Government Survival." Political Analysis 23 (1): 42-58. 